\title{
Sistema Nacional de Contabilidad
}

\author{
Hernán Yacsabuache Pasapera \\ Docente-Facultad de Ciencias Contables
}

\begin{abstract}
RESUMEN
La Ley 24680 o ley del Sistema Nacional de Contabilidad determina las funciones, objetivos y estructura de los organismos y órganos componentes del SNC, instituido por el artículo $145^{\circ}$ de la Constitución Política del Perú de 1979, los mecanismos de coordinación de la contabilidad, así como las relaciones con otros organismos del sector público y del sector privado. Determina, además, que es un sistema autónomo, adminustrativa y funcionalmente, tiene a su cargo la investigación y función de la normatividad de la contabilidad que debe regir en el país, tanto para el sector público como para el sector privado, así como la elaboración de la cuenta general de la República.
\end{abstract}

Palabras clave: Sistema Nacional de Contabilidad, Ley 24680, Contaduría Publica de la Nación, Ley marco de administración financiera.

\section{INTRODUCCIÓN}

El Sistema Nacional de Contabilidad fue creado por la Constitución Política del Perú. Ley fundamental de la nación, promulgada por la Asamblea Constituyenteel 12 dejunio de 1979 , la misma que en su artículo $145^{\circ}$ decía: "La función de unifor mar, centralizar y consolidar la contabilidad pública, así como la de elaborar la cuenta general, corresponden al Sistema Nacional de Contabilidad, el cual además propone las normas contables que deben regir en el país..."

La jerarquía constitucional del Sistema Nacional de Contabilidad se debe a los grandes objetivos que cumple: analizar, registrar, consolidar e informar el movimiento económico del país, elaborar las cuentas regionales, la cuenta general de laRepública y servir de base de infor mación a las cuentas nacionales; además, le cor respondedictarnormas, procedimientos y desarrollar la investigación de la contabilidad para el mejor cumplimiento de sus fines sociales, tanto en el sector público como en el sector no público.

Con la promulgación de la Ley del Sistema Nacional de Contabilidad se completaron las tres bases del trípode sobre el cual descansaba el régimen económico que señalaba la Constitución Política del Perú de ese entonces, ejemplo:

El Sistema Nacional de Planificación, instituido por el artículo $111^{\circ}$ de la Constitución Política del Perú y normado por el Decreto Legislativo N. ${ }^{\circ} 177$, que a través del Instituto Nacional de Planificación, su órgano rector, elaboraba los planes de desarrollo que requiere la actividad del sector público y orienta en forma concertada la 
actividad de los demás sectores, hoy en día el INP ya no existe, fue desactivado por el gobierno fujimorista.

El Sistema Nacional de Control, instituido por el artículo $146^{\circ}$ de la Constitución Política de 1979, normada por el Decreto Ley 19039, que a través de su órgano rector, la Contraloría General de la República, tiene la función de supervigilar la ejecución de los presupuestos del sector público, así como la gestión y utilización de losbienesy recursos públicos. Posteriormente, este sistema se ha venido refor mando con los dispositivos legales vigentes.

El Sistema Nacional de Contabilidad, instituido por el artículo $145^{\circ}$ de la Constitución Política del Perú de 1979 y normado por la Ley 24680, que a través de su órgano rector, la Contaduría Pública de la Nación, tiene por objeto uniformar, centralizar y consolidar la contabilidad pública, así como dictar las normas de contabilidad que deben regir en el país.

\section{EL SISTEMA NACIONAL DE CONTABILIDAD}

La Contaduría Pública de la Nación, órgano rector del Sistema Nacional de Contabilidad hasta el 2004, confor maba un pliego del Presupuesto General de la República como institución pública descentralizada del Ministerio de Economía y Finanzas, según la Ley 24680 del Sistema Nacional de Contabilidad; posiblemente los legisladores, en el debate, no tuvieron en cuenta que la creación del sistema era para operar en todo el sector público nacional y que necesitaba autonomía suficiente en la parte funcional para desarrollar sus actividades adecuadamente, $\mathrm{y}$ por lo menos debió salir como un pliego del Gobierno
Central, en vista de que al Contador General de la Nación lo designa el Presidente de la República por un periodo de 5 años, es decir, sunombramientoerasuperioraldeun ministro de economía y finanzas, quien, por cuestiones políticas, puede renunciar en cualquier momento.

Asimismo, el Sistema Nacional de Contabilidad y los sistemas nacionales de planificación y de control tienen la misma base constitucional de creación (artículos $111^{\circ}, 145^{\circ}$ y $146^{\circ}$, respectivamente); teniendo por norma específica el Decreto Legislativo 177, la Ley 24680 y el Decreto Ley 19039 para cada caso; así mismo, podemos afirmar que los sistemas de planificación, de contabilidad y el de control datan desde antes del virreinato para orgullo de nuestro querido y soberano Perú.

Por tanto, el Sistema Nacional de Contabilidadse constituyó como el custodio del patrimonio del Estado, lo que deter mina aclarar y disponer que la contabilidad en su aplicación pública y no pública es responsable del movimiento total de la situación del activo, pasivo y resultados de los agentes económicos, por lo cual le corresponde la función de control preventivo del movimiento de los bienes y fondos, así como su adecuada utilización; consiguientemente, gozará de la suficiente independencia y jerarquía que le permitan cumplir acabalidadcon susfines, para mayor precisión del sector público peruano.

Pero lamentablemente, con la promulgación de la Ley 28112, "Ley marco de administración financiera del Sector Público", publicada el 28-11-2003, en su artículo $42^{\circ}$, dispone que la "Dirección Nacional de Contabilidad Pública- DNCP, es el órgano rector del Sistema Nacional de Contabilidad". 
actividad de los demás sectores, hoy en día el INP ya no existe, fue desactivado por el gobierno fujimorista.

El Sistema Nacional de Control, instituido por el artículo $146^{\circ}$ de la Constitución Política de 1979, normada por el Decreto Ley 19039, que a través de su órgano rector, la Contraloría General de la República, tiene la función de supervigilar la ejecución de los presupuestos del sector público, así como la gestión y utilización de losbienesyrecursos públicos.Posteriormente, este sistema se ha venido reformando con los dispositivos legales vigentes.

El Sistema Nacional de Contabilidad, instituido por el artículo $145^{\circ}$ de la Constitución Política del Perú de 1979 y normado por la Ley 24680, que a través de su órgano rector, la Contaduría Pública de la Nación, tiene por objeto uniformar, centralizar y consolidar la contabilidad pública, así como dictar las normas de contabilidad que deben regir en el país.

\section{EL SISTEMA NACIONAL DE CONTABILIDAD}

La Contaduría Pública de la Nación, órgano rector del Sistema Nacional de Contabilidad hasta el 2004, conformaba un pliego del Presupuesto General de la República como institución pública descentralizada del Ministerio de Economía y Finanzas, según la Ley 24680 del Sistema Nacional de Contabilidad; posiblemente los legisladores, en el debate, no tuvieron en cuenta que la creación del sistema era para operar en todo el sector público nacional y que necesitaba autonomía suficiente en la parte funcional para desarrollar sus actividades adecuadamente, y por lo menos debió salir como un pliego del Gobierno
Central, en vista de que al Contador General de la Nación lo designa el Presidente de la República por un periodo de 5 años, es decir, sunombramientoerasuperioraldeun ministro de economía y finanzas, quien, por cuestiones políticas, puede renunciar en cualquier momento.

Asimismo, el Sistema Nacional de Contabilidad y los sistemas nacionales de planificación y de control tienen la misma base constitucional de creación (artículos $111^{\circ}, 145^{\circ}$ y $146^{\circ}$, respectivamente); teniendo por norma específica el Decreto Legislativo 177, la Ley 24680 y el Decreto Ley 19039 para cada caso; así mismo, podemos afirmar que los sistemas de planificación, de contabilidad y el de control datan desde antes del virreinato para orgullo de nuestro querido y soberano Perú.

Por tanto, el Sistema Nacional de Contabilidad seconstituyócomo el custodio del patrimonio del Estado, lo que determina aclarar y disponer que la contabilidad en su aplicación pública y no pública es responsable del movimiento total de la situación del activo, pasivo y resultados de los agentes económicos, por lo cual le corresponde la función de control preventivo del movimiento de los bienes y fondos, así como su adecuada utilización; consiguientemente, gozará de la suficiente independencia y jerarquía que le permitan cumplir acabalidadcon susfines, para mayor precisión del sector público peruano.

Pero lamentablemente, con la promulgación de la Ley 28112, "Ley marco de administración financiera del Sector Público", publicada el 28-11-2003, en su artículo $42^{\circ}$, dispone que la "Dirección Nacional de Contabilidad Pública- DNCP, es el órgano rector del Sistema Nacional de Contabilidad". 
Con el mencionadoartículo $42^{\circ}$ dela Ley 28112, desaparece la Contaduría Pública de la Nación, lo que nos da a entender que el Sistema Nacional de Contabilidad baja de nivel jerárquico en la administración pública, que ya no habrá Contador General de la Nación, sino un Director Nacional de Contabilidad dependiente del Viceministro de Hacienda de MEF, como órgano rector del Sistema Nacional de contabilidad.

Para mayor claridad del Sistema Nacionalde Contabilidad, seseñalan algunos de sus principales objetivos:

a) Consolidarlainformación delacontabilidad de los sectores público y no público (privado, cooperativo y autogestionario) para elaborar los infor mes de gestión de la situación financiera del país.

b) Elaborar la cuenta general de la República, quecon el informedelaContraloríaGeneral se remite al Congreso por el Presidente de la República, en armoníacon los artículos $145^{\circ}$ y $200^{\circ}$ de la Constitución Política del Perú.

c) Integrarlosprocedimientosdecontabilidad a nivel nacional e internacional, con la finalidad de uniformar la información de lacontabilidaden el país, determinandouna metodología única en base al sistema científico de la contabilidad.

d) Desarrollar los estudios científicos de contabilidad para fines de desarrollo económico y social del país.

e) Facilitar el estudio global de los agentes económicos del país, asesorar al Presidente de la República en la orientación y conducción de la política nacional de desarrollo en base a la información de la contabilidad que facilite los planes de desarrollo, así como asesorar a los organismos del Estado, absolver las consultas del sector no público en la toma de decisiones que afectan al desarrollo nacional, regional y local. f) Consolidar los balances y estados financieros del sector no público para los fines del balance nacional de la estadística y de las cuentas nacionales.

\section{CONCLUSIONES}

1. La Contaduría Pública de la Nación no debió desaparecer, por el contrario debería haber elevado su nivel jerárquico, como un enteconfor mantedel gobierno central, en vista de que el contador general de la Nación, es designado por el Presidente de la República por un periodo de 5 años, hecho que supera a la designación de un ministro y también porque el sistema de contabilidad se aplica en todo el sector público y no público de la nación peruana.

2. En vezde institución pública descentralizada dependiente del MEF, pudo modificarse la ley de su organización, convirtiéndola en organismo o entidad autónoma, así comoelINPola Contraloríaparaquetenga total independencia administrativa $y$ pueda sacar nor mas referentes al Sistema Nacional de Contabilidad y no esperar a que el ministro del MEF apruebe las disposiciones como era anteriormente.

3. El Colegio y la Federación de Contadores Públicos deberían de dar total importancia al asunto a fin de que se rectifique la Ley 28112 para la continuidad del funcionamiento de la Contaduría General de la Nación con total autonomía administrativa, económica y financiera, y de esta manera pueda emitir las normas que el Sistema requiere.

\section{REFERENCIAS}

Constitución Política del Perú de 1979

Ley N. ${ }^{\circ}$ 24680: Ley del Sistema Nacional de Contabilidad.

LeyN. ${ }^{\circ} 28112$ : Leymarco de administración financiera del Sector Público. 